\title{
The Place, Role and Imperative of the Functional and Informatics Integration of the Economic Situational Information
}

\author{
Tudor Ştefan LEAHU \\ Co-operative Trade University, Chişinău, Republic of Moldova \\ leahu.ts@mail.ru
}

Concepts of economic information are analyzed, transforming, processing, carried out the general classification and elucidated their conceptual content. Also, it's established the place, the role, interconnections and interactions of economic informative subsystems. Starting of the composition and structure of the unitary economic informational process, are highlighted the categories of the stages and operations of this process, the succession of the achievement, current situation ways and prospects of its integral informatics achievement. The necessity of the conscientiousness and consideration of situational information (informative, descriptive) as a decisive factor of the interspersing and interconnection of the material compartment and decisional informational under compartment of the unitary economic administrational process is motivated. The essential factors what motivated the integration of functional and informatics processing of situational information of the unitary economic managerial process are revealed in evidence, enumerated and examined.

Keywords: Notions Of Economic Situational Information, Place, Role, Processing, Unitary Economic Administrational Process, Material, Informational Compartments, Informative, Decisional Under Compartments, Motivation, Imperative Factors, Integration Functional, Informatics Achievement

1 Introduction [6, 386-389; 7, 42-43]

Although in present some users have the impression that the economic informational works are entirely achieved in informatics mode, the reality confirms the fact that many of them are in incipient situation. Such state is characteristic for primary and for utilization stages of the examined information.

In connection with this observation, the major importance became the problems of determining of the place, role and the integral complex informatics achievement of the processing of all information in the environment of the unitary economic informational system.

Both in theory and in practice of the modern management, the unitary economic leadership process is approach almost entirely only from informational viewpoint. But this standpoint such things are simply not done the clear distinction between informative and decisional activities, often the first being considered the managerial. At the same time, the technical - scientifically progress, more real opportunities to be automatically accomplished through the informatics technique, not only informational, but also the material processes, interconnection and interaction with the first, even more insistently impose the approach of economic management process on the unitary positions, thus considering it as inseparable material informational nucleus. Finally, the following of this conception results with the accomplishment of a twenty century dreamthe constitution of the automatically economic unit, formulated by the father of cybernetics N. Viener.

Starting from these observations, has easily gained those two fundamental compartments of the economic unitary management process, but within the framework of the latter - role, place and concept of functioning of the informational situational (informative, descriptive) under compartment, considering it decisive, because through his it ensures the interconnections and interactions between material compartment and decisional under compartment. 
The gradual evolution of economic informational domain and the informatics understructure, which ensure its functioning, required the elaboration of its certain fundamental theoretical conceptions of the organizing, structuring and transformation of the informative (descriptive, situational) information circulating in the medium of the economic managerial system in the pressing interconnection and interaction with the informatics subsystem.

The necessity in such approach is motivated of the existent situation, when the economic informational activities are not affected in the both named mediums, otherwise, respectively "external" and "internal". Because of the permanently pronounced and practical boundless in this sense of dynamics of the economic material processes, what aren't unable evolving without informational matching, it's little possible as the mentioned situation someday so it to change in the direction of it reduction, not even, on the contrary, it so wait intensified.

That is why, both in functional and informatics aspect, the integration of the informational processes and the achievement of their transition from one (the functional) in another (the informatics) and reverse, probably, ever they will remain in actuality. Therefore, they are significantly valuable and they will dispose of the correct estimation and selection on this basis at informatics resources, the following and guidance of their results indisputable are contributes to the efficiency of working of economic informatics system (E.Ic.S.) and, not in the last turn, to the increase of general and professional informatics and informational qualification and culture.

\section{The Existing Situation and the Basic} Notions $[4,462-463 ; 6,389-391]$

The problem of integration of the methods of functional and informatics processing is required by a lot of objective and subjective factors and circumstances, it is taking of the present, but particularly perspective. By virtue of innovation, anticipated of revealing and elucidating the essence of the latest (factors, circumstances), it's necessary to have in view the detailed knowledge, deep awareness and taking in permanent consideration of their, convincingly confirms the need of persevering of the preoccupation of examined problems both the conceptual (theoretical) and practical (applied) plan. In connection with that, first of all it detailed to clarity some new notions derived from the created situation in the domain, determining the role and place of information within the economic management system, in order to become motivated the imperative of the named integration, the contribution to its factors.

Concerning the notions it comes the following: at present and in the foreseeable future it certifies the existence and circulation of economic information in two areas - managerial and informatics. The first is still considered external, because informational processes unfold in the managerial system outside the technical means, while the second is considered rightly internal, the same processes occurring inside of these means.

As mentioned above currently, of those three informative stages of examined information (primary, processing and utilization) only the second is predominant achieved in informatics modality.

Thus, a lot of procedures and operations of these stages, but also some for the data processing, remain fulfilled a manually. Since the economic administration is scoring through certain functions (standardization, regulation, forecasting, accounting, etc.), but lasts, thanks to data transformation, through damaging them with information products, and processing of information within them, in our opinion, can be determined as functional. Such processing is conditioned and starts from the specific of the leadership content of problems of each functions. It's predetermined and therefore decisive influencing the informatics processing; the latest is manifested through various ways of implementing in the physical environment of technical resources. 
The majority of data processing procedures and operations derive from managerial content of problems and isn't fulfilled by the subject. In this case, after the structure, composition and sequence of making it constituted the equivalent of manual, and the informatics is the equivalent of automatic.

Because of the pronounced dynamics of the terminology of investigated domain, is constantly revision, the formulated and used notions. That is why, about the enunciation and elucidation of the sense of the new terms, its soliciting and certain explanations of existents.

In this context, taking it from the beginning, in our opinion, the notion of processing requires some determinations and clarifications. Thus in practice, frequently and in informatics theory, any action expert on the information is interpreted as information processing, regardless of influence or not the latter on their composition, structure and values. In our opinion, in informational environment, this term cannot always be applied in a more generalized sense, replacing any modification of information. Usually, under this notion is understood the calculation processing, unique results in its change of the value of the digital informational units.

Drawing a parallel with the material domain, it may come out that the processing of any resources result in obtaining one finished or semi-finished product. In reality, however, not even deviously any action without failing of the change their composition, structure and value of information and after all do not result in the new product or the prefab. Hence, the more synthesized notion, which would mean any actions exerted in information, is the transformation. Under it is understood any change in the physical presentation form, composition and sequence of distribution of information units within the entities, that include them, their values as a result of information, structural and of calculate processing. Generally, the transformation of information comprises in oneself both the modification of the material appearance, and the composition, structure, value and their content.

Lately, the processing term win the field, which according to $[8,853]$ represent to processing meaning to process the recorded signals on the magnetic tape (support - out) through agency a one processor. As any physical information action is fulfilled and linked, it is thought that the processing is with transformation, but is achieved in informatics technical environment, with its own respective physical proceedings. So, the transformation itself is more to the functional framework, but processing - at the informatics, both being of conceptual (imaginary) character.

Because in any domain, was found to fit the utilization of term the processing. More here are elucidated the problems of the constraint of transition and on this basis - the integration of functional (manual) with the informatics (automatic) achievement of the organizing, structuring and processing through the selection of respective informatics resources of fulfilling the first.

With reference to the categories of information circulating in the economic management system it may be mentioned that depending of their predestination role it stands the situational and decisional information. The first describing the existence and evolution of the managed object (process) in certain moments of time (past, present, future), periods of time (change, day, five days, month of work, etc.), special scales (place of work, crew, sector, section, economic unit, etc.) and the limits of the evolution (rates, settlements, tasks). The second (decisional) constitute the basis of the initiation and guidance of their values during the fulfilled the material activities. Hence the situational information serves as substrate for the formulation of decisional units. At the same time, some of the situational information (of rate - setting, settlement, foreseeing, economic analysis) dispose of the decisional role, since, according to their values, they organized the devolving of the working of the object, is determined the measure of its actions. 
Taking into account these considerations, it may be concluded that the economic situational is thought to be the information what reflects the material situation of the careful management (of fabrication, commercialization, consumption), but economic decisional - the information, on basis of which starts and is organized most efficiently its functioning.

In the bellow study of bibliographic sources we come to the conclusion, in accordance with the accomplished role in the managerial process it may be one synonymization of the situational information with the informative. Both are recently introduced as the undersigned. In this connection, some memberships of economic informatics domain maintaining that the informative information is tautology or that in this case there is and not informative data, which in their opinion, is nonsense. Since, such conception is main, they demand a certain retort to it. First of all such positions are not well founded and correct. In the new dictionary of synonyms $[9,185]$ it comes out that: "INFORMATIVE adj. informational, orientation (Prices)", but in the $[9,491]$ "INFORMATIVE - A. informative, e, adj. What possess all these definitions and those elucidated earlier concerning notions in cause confirm the facts of two varieties of information - informative and decisional. The first only informs through unilateral description, but the second is serving right the basis of starting, guidance and achievement of certain activities. So, such differentiation of information is motivated by their quality such as a component of the managerial process, which includes both the material and informational compartment. Therefore, the right source of report may be serving not only by material object (process), but by its information. Consequently, in the unilateral descriptive aspect is justified and the notion of the informative information.

Starting from the mentioned considerations, the information, which is unilaterally describe (reflected) the object (process) or action, take to hap with molded situations only on a position, considered informative. If not it can serve the basis of decision wording. For example, the accounting information, taken in isolated way, without other categories of economic information express knowing the existence and evolution of the object (process) in the past.

Only in combination with the foreseeing or standardization (settlement) information it contribute to the economic analysis, elaboration and wording of certain decision. All such standardization, settlement and foreseeing information, taken particularly, reflect respectively the limits or amble of the evolution in the future.

To the affirmation, in accordance with which the existence of the informative information causing the supposition, as in this case is there not informative data it may make the following findings. Firstly, do not necessarily start from the contrary. Secondly, the notion is based and is justified of the role of the information in achievement of the unitary managerial process. In the third place, not all information plenary and multilateral reflects (describes, informs), they aren't incomplete, unseasonable, not authentic, approximate, false, etc. In this situation they may be considered not informative. Therefore, depending of what positions are elucidated, the information may be informative or not informative.

Referring to the fact that economic information describes the state of the careful management in certain period of time (the future - forecast, the past - evidence) and in certain limits (rates, settlements), they may be considered right situational. Such information isn't framing in informative and not informative.

Concerning of the place, role, interconnections and interactions of the economic information within the unitary economic managerial system can be formulated in the following ideas.

After the naturalness of the presentation and the specific of functioning (working) unitary economic management system consists at two fundamental compartments - material and informational. Evidently, within the framework of first, they evolve purely 
material processes (fabrication, distribution (commercialization)), consumption, while in environment of the second are achieved purely by information processes (organizing, structuring, processing). In his turn, the letters are too informative the financial administration or informative. In consequence of informative processes it obtains the informative products, but of those financial administration - the decisional products.

3 The Varieties, Place, Role and Conceptual Transformation of Economic Situational Information $[1,845-849 ; 2,89$ $92 ; 4,463-464 ; 5,150-161 ; 6,391-392 ; 7$, $43-45$; $10,56-59$; $11,218-220$ ]

The stress in cause problems primarily is conditioned by the knowledge of the place, role, interconnections and interactions of the economic information with other varieties of such category information. Taking into account the principle of motivation and of formation (obviation) the values of informational units, in relation with the period of the evolution of the material processes all the economic information it divided in two great groups:

- the information what precedes the economic material activities;

- the information what succeeds these activities.

The general classification of economic situational information on the general positions is shown in fig.1.

Both informational groups are of functional content, because these damaging some management functions. In compositional aspect the first group includes the information of rate - setting, settlement and foreseeing the possible material preoccupations. In its turn, those of the rate setting the informational units with the primary and general values, the first being formatted for the elementary technological components (action, operation), and the second - for the constituent order (sub stage, stage, process). Concerning the settlement information, they are of the administrative, constructive and technological content.

If the rate - setting information reflects the limit of the volume of economic (material, time, financial) resources for each technological or constructive unit, then the settlement information describes the order (succession) of the achievement of certain work. Evidently, the information of the technological settlement refers to the passing of the effecting of any work, the constructive settlement - of the strict order of assembly of any constitutive constructive unit (knot, coupling, finished product), while the administrative - at the composition of the executors, their obligations, allotted resources and the terms of accomplishing the acts.

Somehow and the forecast information is of the regulatory character, as by their agency it is determined the necessary terms and resources for accomplishment of task.

Unlike the rate - setting and settlement, such information limits the composition, volume and terms of fulfilling the task. In the case, when the limitation has the attribution at the reduced terms (working shift, day, five days, and decade), the forecast information is considered operative, and the limitation is referring to average term (one month) - they are of current order. Right periodical are the foreseeing information as concerns the terms of the quarter, six months and one year of activity, and long - term duration (of prognostic) - the forecast information on terms 5, 10, 15 and more years.

As a rule, the reflective ray of the operative planning information possessing in such sizes as the place of work (job), brigade (group), subdivision (sector, section) and material economic unit (industrial unit, organization). 


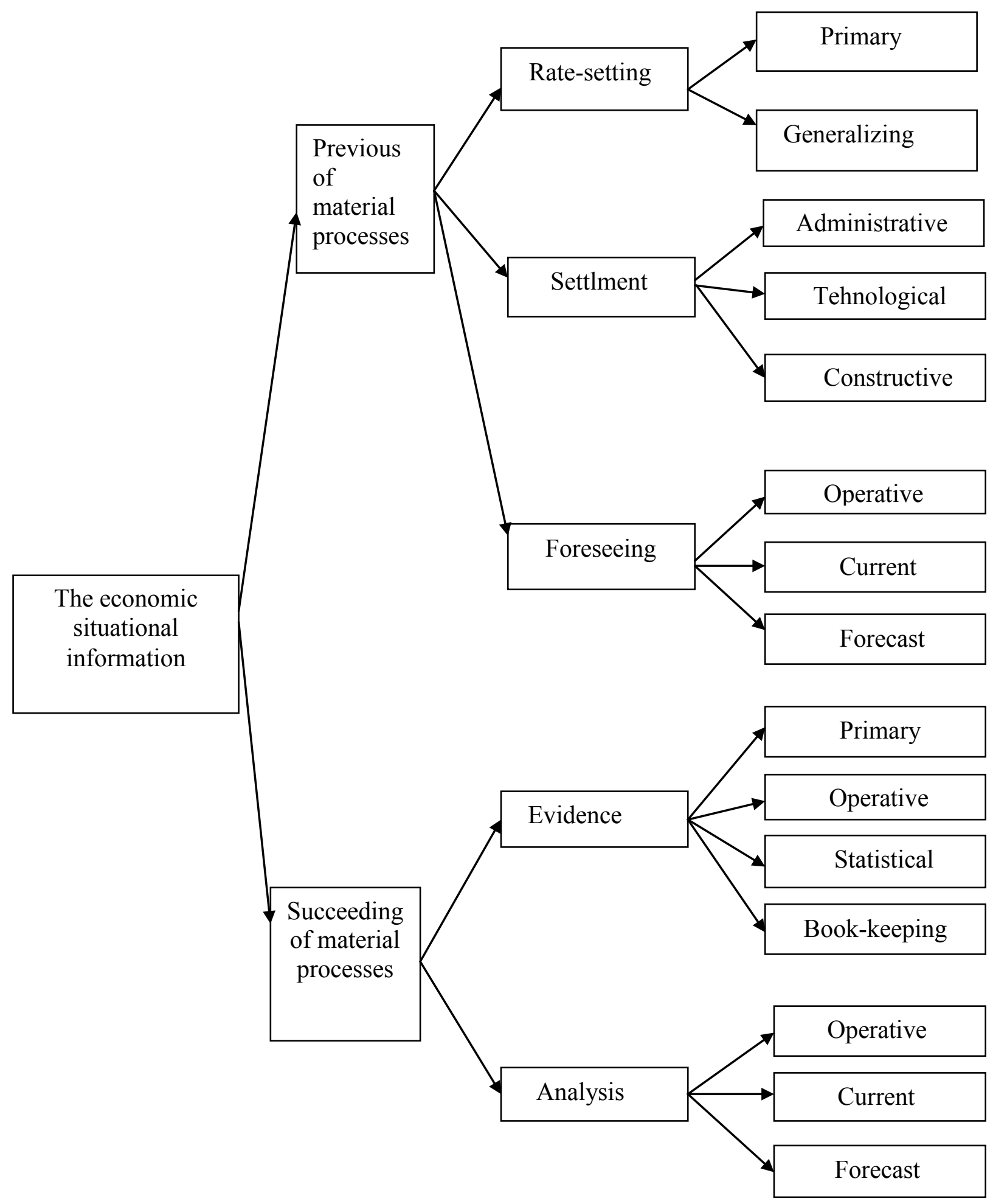

Fig. 1. The general classification of economic situational information on the basis of their functional content and period of theirs formation

The information of current and periodical planning itself reports to the material economic unit and episodic - to the organizational unit of this category. In their majority the prognostic information has the reflective ray in the limits of the organizational economic unit (firm with the essential economic potential, sub - branch, branch and national economy). Each of enumerated special rays constitutes one certain level of economic financial administration. It's established that in the 
national economy itself ten from such levels $[5,41-46 ; 12,28-29]$.

The second group of this information consists of them from the economic evidence and analysis, which after special and temporal rays' composition are identical with those at the first group. More than this, and after the compositional structure of the informational units, they repeat as those of the previously a material economic activities. Such situation is justified of imperative logic of the economic analysis, the first stage of which come in contraposition with the evidence of indicating values with the foreseeing or rate - setting and values of settlement indicators. The contraposition itself effects with a view to determination of the size of deviation (difference) between values of the informational units of both groups, as afterwards to establish the factors, what aroused and the specific weight of the influence of each.

As mentioned both imperative and the composition of the foreseeing, rate - setting and settlement information predetermine the informational composition of economic evidence.

Depending on the situation of unfolding of the material economic phenomenon the information of the elucidated groups (previously, successor of material processes) can change with the place. So, in the case, when such phenomenon is found in the incipient situation, therefore, it foresees to be achieved (to be put into function), such intention being able to produced only after the formation of the rate - setting, settlement, as well as foreseeing information. At the same time, if the material phenomenon is fully unfolding, being satisfied for multiple times, only after formation of informational values of the evidence and analysis may be formulated, tacked and realized the values of the decisional units.

The graphical interpretation of such two variants of the logic of succession training (obtaining) of functional economic varieties information is shown in the Figure 2:

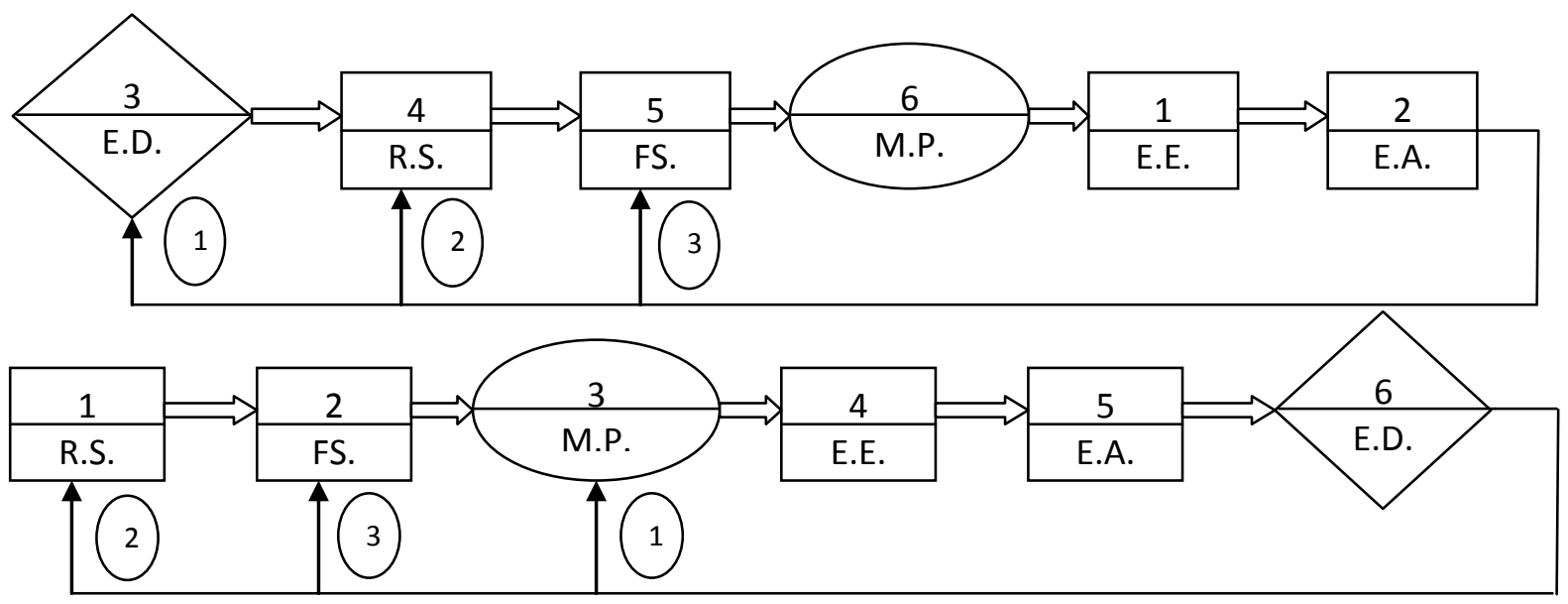

Fig. 2. The graphical showing of the variants at possibly successions obtaining the values of functional economic information

In the schemes of the Figure 2 are admitting the next significations:

- R.S. - the rate - setting and settlement information;

- FS. - the foreseeing information;

- M.P. - the material processes;

- E.E. - the economic evidence information;
- E.A. - the economic analysis information;

- E.D. - the economic decisional information.

The numbering in the upper part of the blocks reflect the direct direction to the formation of values of varieties at the information, but the numbering in the circlets 
(on the bottom part of the blocks) - the reverse direction of such formation.

The scheme of the variant 1 demonstrates that in the case, when the material process is new and it foresees to be initiated for the first date it requires firstly to be determined the composition and calculated the values of indicators of the rate - setting and settlement (1), as with their helping so being calculated the values of the indicators of the foreseeing (2). According to the lasts putts into function the material processes (3), but the results of their functioning are determined thanks to obtaining the economic evidence information (4). Possessing the information what reflects the foreseeing $(1,2)$ and real (de facto) (4) evolution of the material process (3), may be obtained the information of the economic analysis (5), within the framework of its formulating the respective decisions (6). The last directly influencing the going of the material activities (1) and guiding first of all at the revision (correction) of the values of rate - setting and foreseeing indicators (2) and the fresh calculation of foreseen indicators (3), according to in the new variant evolving the material processes.

The second variant of the elucidated schemes confirm the fact that in case of finding in the functioning situation (achievement of multiple date) of the material processes, firstly they forming the information of the economic evidence (1), because the information of the R.S. (4) and FS.(5) has been obtained from the stage of their initiating, they exist already. In such a situation there are created all the conditions from effected economic analysis, to the information products of formulation of decisions(3), their correction (1) and of the values of standardization and settlement (2), as well as foreseeing information (3), but in their agency - and of the material processes (6).

From all those analyzed so far it becomes evidently that the economic evidence information permanently is formed after the passage of the certain period of functioning of the material process, has pure informative (descriptive) character, occupy the intermediate position between material and decisional processes, in joining with other varieties of information contributing to the formation (obtaining) of economic analysis information, formulation of the adequate decisions and correction of previously material activities information.

So, any information at the pure descriptive content, that reflects the previous evolution of the object (process), is considered at the evidence. If such information referrers to the processes and production, distribution and consumption of the material and spiritual goods, they are of the economic content.

The notion of the economic includes the primary, operative, book - keeping and statistical evidence (Figure 1).

To the basis of the fabrication of book keeping and statistical informational products stays the initial data obtained within the framework of primary evidence. Only the modalities of their gathering and systematization differ. Procession the economic evidence includes the achieved procedures and operations shown in Figure 4. Any management process, including the economic one, takes place on the basis of the multiple organic interconnections and interactions among of which three essential compartments, such as, the material, informative and decisional. Depending of the domain of functioning may be discreet or continuous order. As a rule, the last modality of one's own for the pure material activities within the framework of one thing of several actions (operations), while the discrete refers prevalently to the co - ordination of these activities in the above mentioned rays and regimes. Therefore, the analogous (uninterrupted) modality is characteristic especially for the material compartment of economic unitary managerial process. This is explained by the fact that in majority on activities are fulfilled at the subject of enough compact space and time (within the framework one job or one subdivision group, sector, section, which allows operatively at to intervene with certain modifications in any moment on the route of first shift, working day). 
Simultaneously, at the level of material organizational shape (economic unit, sub branch, branch, national economy) the effecting of material activities is possible through at their co - ordination at a distance in miscellaneous new temporal and long standing terms. From this reason within the framework of the organizational material units it's enough evident and pronounced the discrete (interrupted) character of economic material activities.

Certainly, any activity at any category, either material or informational, disposing of certain discretion, very much is achieved through the decomposition in certain component parts and achievement in the last certain succession. But at those affected within the framework of each job or subdivision the spatial and temporal rays are so reduced, that conventional it may establish their continuity. In such a situation and the informative and decisional informational necessities are enough confined, very much as the actions (operations) taking place to the physical capacities of subject through directly visual monitoring and in her base material reaction, in accordance with the certain instructions at the achievement of work.

If the material activities, in dependence of the level of their accomplishment, disposing at different character (at the initial continuously, at derived (superior) discreetly), then the informational, regardless of manageable level, having the discreet character, because that it effectuates after the expiration of the material minimum, after one shift.

The modality of accomplishment of activity (continuously or discreetly) leaves one's mark of the informatics aspect of her achievement. So, in the continuously case are necessary the technical means, which are operating with the physical units, what putting in function or stopping on a certain process, while for the discrete it's characteristic for the implication for more resources in joining, their interconnection rarely having place. In connection with those elucidated till now it certifies that in strategy of informatics achievement of economic managerial system they must first of all lean against the account of the modality of fulfilling of economic activities (material, informative, decisional) - continuously or discreetly - and at the succession of their spatial and temporal interconnections and interactions. Such a conception of their approach can be admitted and applied in the event, when the leaded object is conceived right unitary material - informative nucleus, but its leadership process is thought to integrate material-informative-decisional activity.

This variant of treatment inquires the inversion of the orientation at invention, implantation and functioning of the economic managerial system in informatics modality. The essence of this reversal consisting in that what if initial and in majority and at present firstly taking place the invention of technical means and technological (organizational) methods, afterwards is establishing the concrete domain of their efficient application, then once becoming evident the necessity of the elaboration (projection) and application of those means and methods in ground qualitative and quantitative parameters of the respective domain. Thus, the informatics technical policy is necessary to be orientated from means and methods to their application, but conversely, from the domain - to the necessities in means and methods of putting in deeding and permanently functioning of this domain. More so then this the evolution of the informatics technique even more evidently confirm the fact of increasing its flexibility in sense of their adaptation at any domain of application.

That is why the existent situation and the forthcoming prospect requires the primary establishment of composition of the works proper of the domain at leaded activities, objects and resources with all values of its quantitative and qualitative parameters, on basis of which it effects their leadership. In this context it coming out that off the unitary positions the economic managerial system 
comprises the fundamental phases, schematically presented in Figure 3.

Of these positions, the transformation of the information, as and their organizing, disposing of the same two aspects of the main three stages: appearance ("birth"), processing ("development") and utilization ("death") or the transition from the informative at decisional information.

This scheme evidently demonstrates the extreme complexity and immense globalist of the composition of each compartment and phase of works, with the miscellaneous pronounced ramifications, especially, concerning, the material. As a result, the modality of their approach requires it to be of systemic order, but their treatment - of conceptual order.
To confirm this situation it's sufficient to enumerate those works what are proper only for the informational informative sub compartment, as well as the material information: L.O. - leaded object; A - the stage at the appearance (obtaining) of initial (primary, elementary, intermediate) informational informative units; $\mathrm{P}$ - the stage of their processing; $U$ - the stage of the utilization of informational informative products; D - decisions. Compartment and decisional sub compartment are individualized of each real resources, object and activity. Therefore, the conceptual elucidation of these two compartments (material and informational) is not so much eloquent.

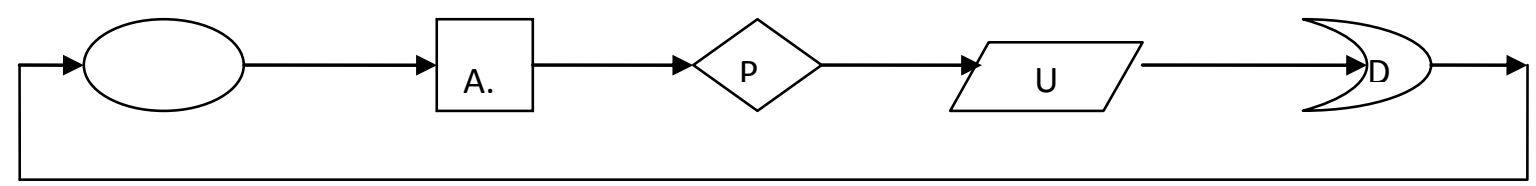

Fig. 3. The composition and interaction of the principal stages at transformation of economic

In dependence of the functional variety and concrete parameters, the economic information passes through miscellaneous stages and processes of transformation on diverse succession. But for the majority at they aren't characteristic for the transformative stages and operations presented in Figure 4.

As it is evidence that the ,birth" of information take place on the basis of identification of the specific features or the produced changes in the leaded objects through measurements and calculations.

As well as the primary and initial information units at one level of economic leadership (those of the evidence and rate-setting - at the inferior level, those of planning - at the superior level) existing the necessity of their memorization, achieved thanks to registering on the miscellaneous supports (manual, technical). Such a necessity is motivated, also, all of their economic, gestational and juridical importance which can be capitalized in miscellaneous spatial and temporal rays. Concomitantly, with the festering on the support, it produces the coding and multiplication.

The first work (coding) arouse on the specific character of the informatics means and methods of data processing, although it is not excluded that being sometimes effected and in the milieu of the manual processing, because often there are more economic presentations of information. Simultaneously, the multiplication is produced in the events of the concomitant utilization of values of some informational units in more places of a lot of users.

Both extractions and registering of values of the initial information is effecting descended, while their processing, as a rule, takes place in a centralizing modality. About one, the place of the processing of these values is situated at the certain distance of the places of their forming (obtaining). At this reason the extraction and recording aren't succeeded of transmission the initial informational units values from the places at their processing, with this operation being ended the works of the "obtaining of raw mater" - at informational units of primary and initial 
values, what and constitutes the basis of forming of information with the derived values.

At the same time, the transmitted primary and initial information don't suddenly process, for one certain term being stocked and that is why it's necessary the organization of their storage. As mentioned the examined operation itself referees not only to the information with the variable values, but at these with the relative constant values, the last requiring the long keeping of juridical and strategically intentions.

Very much as not all information is submissively at simultaneous processing it imposes the retrieve only of those which aren't necessary at once. Subsequently, structural and calculation processing take place the concluding of the obtained results in accessible form for end users, which effects, also, through recording. The multiplication is motivated by the same circumstances that within the frame work of operation with the same name the affiliation at the first stage, but the decoding - of the data transformation (the physical (informatics) informational units) in the functional informational units, which may be spotted and awareness of the user. Lastly, the derived (resulting) informational units, concluded in certain form (well - informed) aren't provided (submitted) to the end users (functional workers), who are interested in the analysis of their values.

But, and this stage not all information are suddenly at analysis and that is why preliminary is necessary to do concerning their same operations, which at the second stage, is tied with their organizing, resenting and retrieving. Being retrieved, the necessary informational units, their values aren't analyzed. This last informative operation is achieved firstly through counter putting of the values of informational units affiliation of miscellaneous gestational subsystems in miscellaneous combinations, as by example, those at evidence computing with those of foreseeing or of the evidence with those of rate - setting etc.. In the case of hunting out certain deviations molded in result of these comparing is determining the composition of the factors, which contribute to their, influences the economic material activities, the weight of each in the general (total) value of deviation.

On the basis of establishing the composition of factors (reasons) at influence and of their weight in the traced deviation, in continuation it determines the actions, participants and necessary resources not admitted in the future or to encourage the characterized tendency of the deviation in the previous term, the period of achieving the actions and methods (proceedings) of verifications of quality and complete fulfillment at stipulated actions. All these activities institute the content of the first stage of initiation at management, which is reduced at formulating and taking the decisions. Once with the achievement of this stage take the place the ,eruption" of decisional information from those informative within the framework of the leadership process, or transformation of informative information in decisional.

Concerning the achievement decisions, it may be affirmed that in majority it take place through the agency of the material activities, although without the guidance of certain information it may be effected.

At the offered scheme of the Figure 4 it's evident that the composition of works of the informative order is very varied, but the achievement of each have pronounced specific. Respectively, the composition of the technical means and informatics technologies isn't of the same character.

Such an approach requires the necessity of elaboration firstly of such arrow of technical means, which have automatic achieve of each works that are contained in the scheme. It can include in only one technical mean of the possibilities at automatic affection of all works.

Until present it is observed one certain success at the second way, obtained through the creation and equipment of computers with such device, how it's the modem, what permit to fulfill the new function of data change at the distance. 
Stages

Operations

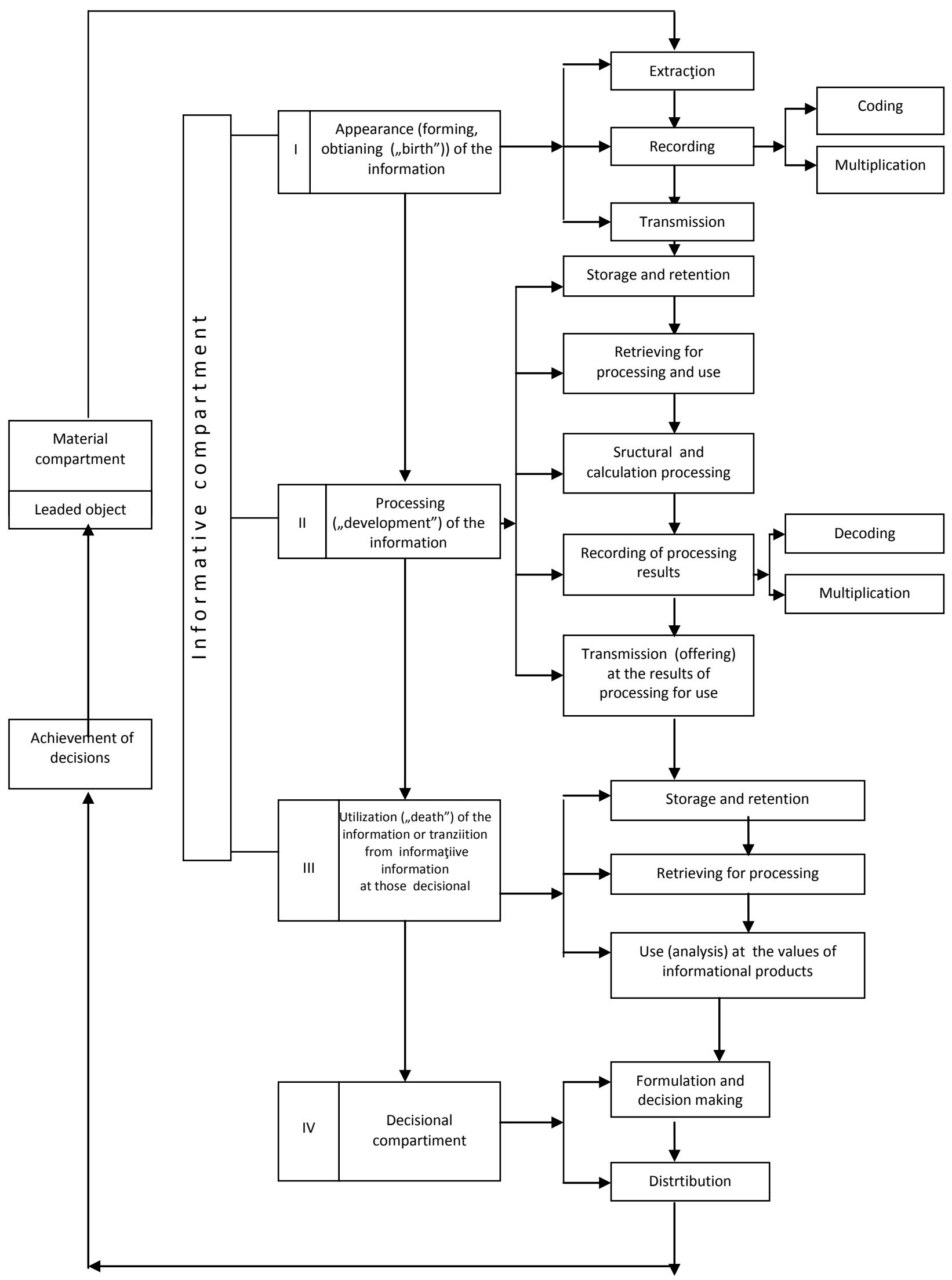

Fig. 4. The composition and the content of the stages at processing (transformation) of economic informative information 
The prevalence of one at these two ways depends on performance of the classic sciences (physique, chemistry, biology, etc.), at the level of application of these performances in economic informational domain and of technical - scientific progress. The present level and the visible practical prospect of the evolution of these sciences conditioned the basis of the strategy of informatics achievement at the economic managerial system on the electrical effects, what ensures both the reliability and the performance of flexibility of this system in the material environment of its functioning. According to this orientation the apogee in cause strategy will be in such a situation, when the solving of the informational problems will occur through the agency the physical (chemical, biological, etc.) models, in such a manner eliminating many existent interfaces in the shape of the internal informational, programmatically and technological resources.

The same composed variety of economic informational activities, also showing the necessity of revising the general notion at „computing technique”, under that, usually, is understood any technical mean involved in the unitary economic informational process, and it substitution with the term ,informatics technique”, which, in our opinion, is far greater adequate.

Except the information with the informative role, still there distinguish the information of the mixed role, what both within the framework of the processing, the end their using, disposing of both role they to the information of economic analysis. In their composition right informative can be considered the information obtained at the first stage of analysis, from which are obtained the values of the deviations (positive, negative) of the real situations of evolution of the objects (processes) from those planned (standardized, regulated), identifying the factors of the influence, the weight and size of the general value of deviation. At the second stage are scored the information of the gestational importance under the sway of the decisions, formulated on the basis of the informative products obtained at the first stage in cause analysis. Finally, these decisions aren't fulfilled through the change of the values of the planned charges, norms of consumptions, tariffs, prices, etc., as well as of administrative, technological, constructive settlements etc. As for achieved the direct role in the process of working of the unitary economic leadership system it certifies the next situation: the previous information of the economic material activities (of rate setting, settlement, foreseeing) achieving the direct connection, but those that succeed these activities (of the evidence, statistics, analysis) - the converse connection between the leaded object (process) and the management system

Therefore, at the moment the informative under compartment is achieved in two domains (financial administrations and informatics), it imposed the elucidation of the place and evolution in each of them, with respectively their integration. The last ensures the automatically functioning of the leadership process in integrity.

In the event of managerial environment, at the level of compartments, the compositional structuring, the highlight of the succession of interconnections and interactions of the constituents of elucidated system are shown in the Figure 5. In accordance with the Figure 5 the tidiness of the descending decomposition at the make-up of Su.e.m., in the constituent component parts, can be described through the following analytic structural formula in the next succession:

Su.e.m. $\equiv C m l V C i l(1) ; C m l \equiv P m l V R m l$ (2) Cil $\equiv P i v V P g l$ (3);Ril $\equiv$ Ris VRid (4)

The examined scheme is elaborated starting from the principle of the motivation that predetermines the following consecutively of the processes of functioning of Su.e.m.:

$$
\text { Su.e.m.: Pm } \longrightarrow P i v \longrightarrow P d l
$$

But, it is not excluded the route of the evolution of each categories of processes so they produced tasks (returns, comparing 
(verifications)) towards the reality of the material, informative or decisional environment. That is why the above order is one's own for the situation when managed object (process) is in dynamic situation. If its activities aren't at the initial stage, then the elucidated order oneself presented:

$$
\mathrm{Pdl} \longrightarrow \mathrm{Pml} \longrightarrow \mathrm{Piv}
$$

The same scheme and the analytic formula (3) - (5) confirms the fact that in integral gestational process the situational information occupies the intermediary position, being formatted in the following of evolution of the material activities as after either processed at the managerial system with the goal of obtaining the values of decisional units, what in continuation are offered of leaded object to ensure in accordance the last of its evolution of remotely. In such sense the value of the examined information is predetermined at their role at "primary matter" of starting the gestational process. From this point of view in environment of custom system are at the decisive predestination, as well as their absence leading to the interruption and impossibility of unfolding the indissoluble gestational process.

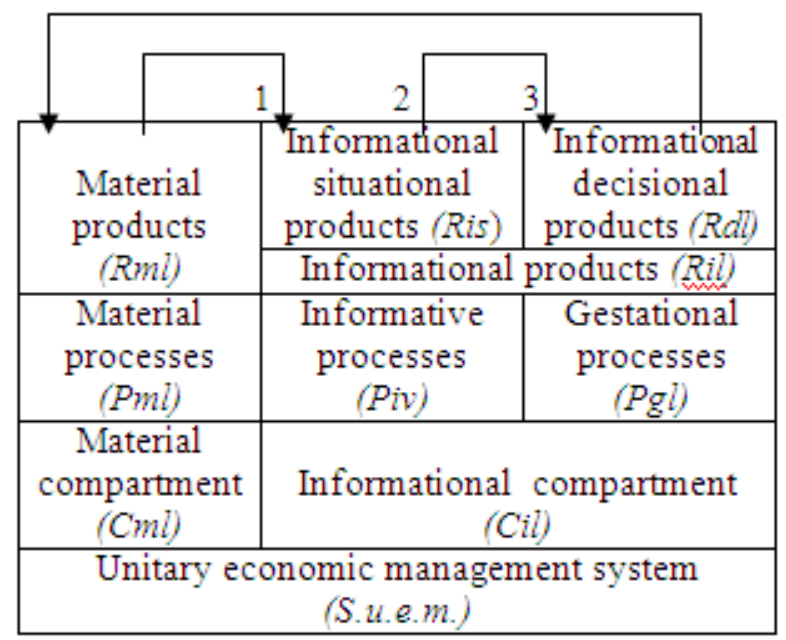

Fig. 5. The conceptual scheme of the composition of inclusion, succession of achievement the interconnections and interactions of constituents of unitary economic management system
At the level of the served leadership functions, the composition, structure, succession of the interconnections and interactions of the constituents of the informative under compartment at the unitary economic leadership system are shown in Figure 6.

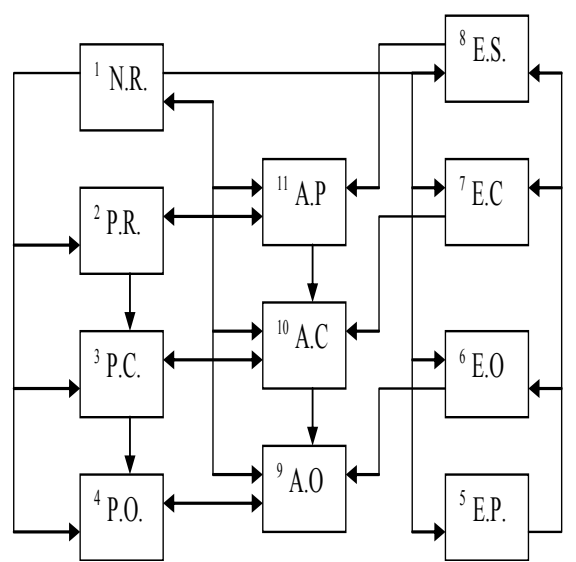

Fig. 6. The composition, structure, succession of the interconnections and interactions of the constituents of informative under compartment of the economic unitary system

In the custom scheme right the constituents are considered the informational informative under systems, but the numerating is applied to demonstrate the order of their formation. Such, with $1-4$ are numbered the under systems what form the values anticipated of the initiation and evolution of the economic material activities, with other numbers - the under systems, which succeeds these activities, primarily those with numbers 5 8 , and in final - those numbered with the numbers $9-11$.

The interconnections and interactions between mentioned constituents are motivated at two goals - to be used (analyzed) or to be processed. In the present scheme showed be taken into account both goals. That is why, through utilization of the numeration of examined under systems, the variants of the order of functional and transformative integration of the values of their informational units can be described with the followings analytic formula (schemes): 


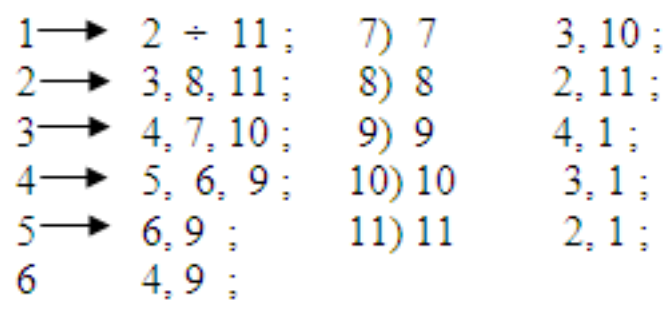

At the presented schemes it is evident that the values of the informational units of rate setting and settlement (1) are processed and analyzed of all other under systems $(2 \div 11)$, while those of the forecast under system (2) for the under systems of the current foreseeing (3), statistical evidence (8) and current analysis (10). Simultaneously, in the result of the affection the economic analysis $(9,10,11)$ is possible to intervene with certain corrections of the planned $(2,3,4)$, normalized or of settlement (1) indicators. Evidently, the obtaining of the values of the informational units of the operative analysis under system (9) entailing the implication in common of the indicators of under systems 1 , $4 \div 6$, of the currently analysis (10) - of the indicators of under systems $1,3,7$ and of the analysis of forecast (11) - of the indicators of under systems 1, 2, 4, 8 .

The automatic integrated organizing, structuring and functioning of the components of informative under compartment can be achieved in the shop of data bank, what it's of the informative and intelligent nature. The first produce the informative, but the second - the decisional products.

4 The Imperative Factors of the Integration of the Functional and Informatics Processing of the Economic Information $[4,465 ; 6,392-393 ; 7,45-46]$

Based on the done findings it way be mentioned that any preoccupations of investigative, elaborative and functional order of such information always are current and important.

Once with the establishment of the existence and working areas ("external", "internal"), of level at the covering of transformative processes of informatics means and methods, of contribution to the achievement of the management functions, of concordance with the aspects and modalities of their elucidation (functional - manual, informatics - automatic), as well as the clarification of the notions of transformation, processing, synonymization of situational (descriptive) with the informative information, it creates the conditions to found the imperative of integration of functional and informatics processing of the situational information.

In this context it may be mentioned the following decisive and contributive factors which objective requires the preoccupation of such integration:

1) the permanent trend towards automatic (not automation) processing in interconnection and interaction initially of both categories of informational resources (situational, decisional), but of the final - and of material resources with these informational in the same integrated modality. Such mode of approach in the end contributes to the constitution of economic unit - automation;

2) such conception requires the integration of the functional (manual) with the informatics (automatic) processing, of under compartment which can be archived in the scope of data bank what is of informative and intelligent nature. The first produce the informative, but the second - the decisional products

The material with the informational works within the framework of unitary management system;

3) such integration of elucidated processes is the preliminary order and contributes to:

a) highlighting the full composition and fastening of the logic of succession of interactions between operations of the unitary transformational informational process, starting with organizing, structuring and finalizing with obtaining the informational finished product;

b) the classification of operations of this process in manual and automatic carried;

c) highlighting the modalities of transition from manual to technical operations;

d) fastening and elaboration of informatics interfaces, which ensure such transition; 
e) supporting of automatic continuity of achievement of integral informational processes.

4) the economic situational informational field is significantly partly covered by informatics means and methods, practical all their workings only of the processing stage;

5 ) this covering contributes to supporting the automatic evolution of management functions;

6) since the moment a lot of operations of all three transformative stages are manually effected, the present problem, but and, especially, for the future is the insurance of the easing, slowing and without suspensions from the manual to the automatic transition. In this sense primordially it's necessary to establish the composition and possible proceedings of achieving the operations in both environments (manual, automatic) for the integration (inclusion) within the framework of unitary informational process;

7) at thoroughly automatic achievement of management process contributes the totally approach;

8 ) in the labor of the processing more at the $70-75 \%$ occupies the informational and structural procedures;

9) the rational organizing and structuring of information increases the efficiency of their processing;

The profound knowledge, the awareness of the impartiality role, place, essence of the economic situational information, the guidance of the integrated conception of their functional and informatics processing, finally offering the conditions for both material, and spiritual prosperity of the human society.

\section{Conclusions}

To date the accumulated experience and formulated theoretical theses concerning both informational the and those material activities permit taking evident the following general trends and directions of informatics achievement at economic, as well as an economic evidence informational respectively system and subsystems :

1) improving the technical basis on following directions: a) extension the functional capacities of technical means;

b) as much as intense and massive utilization of the performance constructive elements and the effects of physical (chemical, biological) modern processes in construction of these means;

c) maximum miniaturization of the clearance diagrams at the informatics technique with the concomitantly continuously extension of „capacity” of solving at economic informational issues;

d) maximum facility of functional access at the any category users of in cause means through agency definitive simplifying their exploitation;

2) modernization of the technologies of fabrication at the informatics technical means in basis permanently unification at constructive elements and their assembling through conveyer method;

3) continuously elaboration of the concepts and timely application at gradually shapes of functioning at the economic informatics managerial system, granting the priority of technical factor comparative with the organizational, previous the last being predominantly, but in present and in future low down -entirely;

4) thoroughly and complexly (in interconnection) accomplishment at all the stages of functioning at the economic managerial system, which contributing to:

a) as well as rational construction and at increase of consciousness at this system;

b) brining into full compliance at the informational with those material enshrining of their distributive concordantly organizing and effecting;

c) automation of the majority economic activities grace informatics achievement at the informational connections between them;

d) maximum loading with work of informatics technical means;

5) orientation the classical sciences to application they obtained investigation results within framework of their invention, elaboration, implantation and functioning domains of the informatics technique; 
6) intensive preparation, scientifically motivated, thoroughly and adequate for the prospects activities at the future specialists necessary for the miscellaneous domains of economic informatics;

7) constitution the gradual shapes and setting up new scientifically branches in the elaboration, implantation and functioning of the economic informatics managerial systems (E.Ic.M.S.).

The thoroughly and entirely knowledge at the aspects of strategies informatics achievement of economic, inclusively and the economic informative informational, managerial activities, as well as at the tendencies and general directions of evolution at performances of this achievement will contributing of one integrant informatics system of fabrication at material, informative and decisional products of economic order with the essential functional efficiency.

\section{References}

[1] T. Şt. Leahu, "The evolution, specific and problems of constitution and functioning of automatized banks of intelligent economic data (A.Bn.Ig.E.D.)," The proceedings of the seventh international conference on informatics in economy, Bucharest, May 2005, INFOREC Printing House, Academy of Economic Studies, 1414 pg.

[2] T. Şt. Leahu, "The functional conceptual aspect of the composition, structure and working relations of the automatized banks of intelligent economic data (A.Bn.Ig.E.D.)," Volume $X$, 2006, The 2nd supplement of the review "Informatica economică", International Conference "Knowledge management, Projects, systems and technologies". Bucharest, November, 910, 2006. Volume II, 237 pg.

[3] T. Şt. Leahu, "The Conception of the General Content of the Composition, Structure and Working of the Informative Components of the Economic Knowledge Base," Informatica Economica Journal, Vol. XII, Nr. 4 (48), pg. 105-112, Bucharest, 2008, 138 pg.
[4] T. Şt. Leahu, "Imperativul integrării procesării funcţionale şi informatice a informaţiilor situaţionale economice," Academia de studii economice din Moldova, Materialele Conferinţei Ştiintifice Internaţionale „Republica Moldova: 20 de ani de reforme economice", 23-24 Septembrie 2011, Vol. I, Chisinau, C.E.P al A.S.E.M., 2011, 295 pg.

[5] T. Şt. Leahu, "Organizarea, structurarea şi transformarea informaţiilor sistemului managerial economic," Monografie. Chişinău, Centrul Editorial Poligrafic al Universităţii de Stat din Moldova, 2009, $421 \mathrm{pg}$.

[6] T. Şt. Leahu, "The motivation of the imperative of integration the functional and informatics processing of the economic situational information," The Proceedings of the 11-th International Conference of the Informatics in Economy (IE-2012) „Education, Research and Business Technologies", 10-11 May, 2012, Bucharest, Romania. Published by Bucharest University of Economic Studies Press, 548 pg.

[7] T. Şt. Leahu, "The role, place and functioning the informative (informational situational) under compartment in the environment of the automatized banks of economic intelligent data (A.Bn.E.Ig.D.)," The proceedings of ARA'36-th International Congress ,Learning without frontiers. Presses Internationales Politechnique, Montreal, Quebec, Canada, 2012, 240 pg.

[8] DEX. Dicţionar Explicativ al Limbii Române. Ediţia a II-a, Univers Enciclopedic. Bucureşti, 1996, 1192 pg.

[9] L. Seche, M. Seche, I. Preda, Dicţionar de sinonime. Nou. Ediţia a III-a, revăzută şi adăugată, Bucureşti, VOX, 452 pg.

[10] The place, role and problems of the integral complex informatics achievement of processing of the economic evidence information. Materialele Conferintei Internaţionale. Bacău, Universitatea "George Bacovia", 2012, 272 pg. 
[11] T. St. Leahu, "Tendinţele extinderii spaţiului informatic de acoperire a activităţilor informaţionale informative economice," The 33-rd Annual Congress of the American Romanian Academy of Arts and Sciences (ARA), Proceedings, Volume II. Politechnique International
Press, Montreal, Quebec, 2009, 492 pg.

[12] F. S. Leahu, "The economic information: organizing, structuring and transformation," Chisinev, 1996 (rus), $220 \mathrm{pg}$.

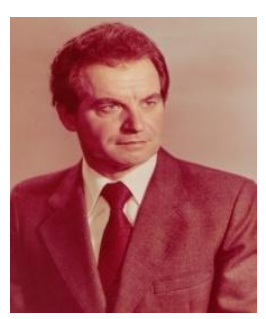

Tudor LEAHU has graduated the Faculty of Economics of State University of Moldova in 1960. He holds a PhD diploma in Economics from 1966 and he had gone through all didactic positions since 1966 when he joined the staff of the Chisinau Polytechnic Institute (at the present - Technic University of Moldova), teaching assistant in 1966, senior lecturer in 1968, assistant professor in 1970. Currently he is the Department Head of Economic Informatics Systems of Faculty of Accounting and Economic Informatics of Cooperative Trade University of Moldova. He is the author of more 15 books and 200 journal articles, thesis in the domain of elaboration, implementation and working of the economic informatics systems (E. Ic. S.), economic informational systems and data structures, informational and informatics technologies, the economics, protection and efficiency E.Ic.S. His work focuses on the organizing, structuring and working of situational information of the economic managerial systems. 